\title{
Tolerance for Uncertainty and Professional Development: a Normative Analysis
}

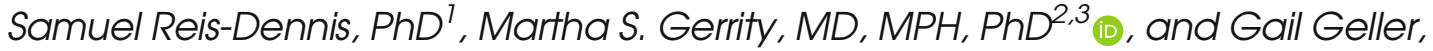 \\ $S C D, M H S^{4,5}$
}

\begin{abstract}
${ }^{1}$ Alden March Bioethics Institute, Albany Medical College, Albany NY, USA; ${ }^{2}$ Division of General Medicine and Geriatrics, Oregon Health and Sciences University, OR Portland, USA; ${ }^{3}$ Section of General Medicine, VA Portland Health Care System, OR Portland, USA; ${ }^{4}$ Johns Hopkins Berman Institute of Bioethics, Johns Hopkins University, MD Baltimore, USA; ${ }^{5}$ School of Medicine, Johns Hopkins University, MD Baltimore, USA.
\end{abstract}

\begin{abstract}
Scholars from a range of disciplines including medicine, sociology, psychology, and philosophy have addressed the concepts of ambiguity and uncertainty in medical practice and training. Most of this scholarship has been descriptive, focusing on defining and measuring ambiguity and uncertainty tolerance or tracking clinicians' responses to ambiguous and uncertain situations. Meanwhile, scholars have neglected some fundamental normative questions: Is tolerance of uncertainty good; if so, to what extent? Using a philosophical approach to these questions, we show that neither tolerance nor intolerance of uncertainty is necessarily a good or bad trait. Rather, both tolerance and intolerance of uncertainty can give physicians advantages while at the same time exposing them to pitfalls in clinical practice. After making this case, we argue that cultivating certain virtues-like courage, diligence, and curiosity - could help clinicians avoid the dangers of excessive tolerance and intolerance of uncertainty. Finally, we suggest that medical educators develop curricula and career counseling beginning with matriculation and proceeding through specialty choice and residency training that explicitly address trainees' responses to clinical uncertainty. These programs should encourage trainees, students and residents, to be mindful of their reactions to uncertainty and help them develop virtues that will allow them to avoid the hazards of extreme tolerance or intolerance of uncertainty.
\end{abstract}

KEY WORDS: uncertainty; medical practice; normative analysis; ethics; medical education.

J Gen Intern Med 36(8):2408-13

DOI: $10.1007 / \mathrm{s} 11606-020-06538-\mathrm{y}$

(c) This is a U.S. government work and not under copyright protection in the U.S.; foreign copyright protection may apply 2021

$\mathrm{O}$ ver the past 30 years, scholars from a range of disciplines including medicine, ${ }^{1-4}$ sociology, ${ }^{5,6}$ psychology, ${ }^{7-11}$ and philosophy ${ }^{12,13}$ have addressed the concepts of ambiguity

Prior Presentations: None

Received August 30, 2020

Accepted December 21, 2020

Published online February 2, 2021 and uncertainty in medical practice and training, including several notable reviews. ${ }^{6,7,9,10,14,15}$ Interest in uncertainty has reemerged in response to recent advances in medicine ${ }^{16}$ and the impact of uncertainty on physicians' well-being. ${ }^{17,18} \mathrm{In}$ light of the current COVID-19 pandemic, the subject of uncertainty has taken on new significance as healthcare providers face unprecedented uncertainty both inside and outside of the hospital. ${ }^{19}$

We explore how tolerance and intolerance for uncertainty might shape physicians' response to uncertainty. Uncertainty is not merely a condition healthcare providers find themselves in during crises, but an inescapable part of everyday medical practice. ${ }^{4}$ It will not disappear with the emergence of a vaccine or an effective public health strategy ${ }^{6,19}$ but is present throughout medical careers.

Most scholarship on tolerance for uncertainty focuses on how to define and measure it. ${ }^{14}$ Strout et al. identified 18 measures of uncertainty and ambiguity tolerance in their systematic review. ${ }^{15}$ Definitions of ambiguity and uncertainty varied, and few studies included a conceptual model to guide development of measures. ${ }^{14}$ Strout and others developed an integrative model of uncertainty tolerance. ${ }^{14,15}$ They suggest that ambiguity, complexity, and probability are properties of a stimulus (a clinical situation) that make the stimulus hard to understand ${ }^{15}$ and uncertainty is an individual's conscious awareness of their ignorance. ${ }^{15,20}$ Parallel with these efforts, another body of literature addressed the role of medical education in rewarding certainty ${ }^{4,21}$ and the need for a cultural shift that acknowledges and embraces tolerance for uncertainty. ${ }^{4,20,22}$

This paper aims to answer fundamental normative questions that existing literature has not directly addressed: is tolerance for uncertainty good; if so, to what extent? In answering these questions, we argue that neither tolerance nor intolerance for uncertainty is necessarily a good or bad trait. Rather, both tolerance and intolerance for uncertainty give their bearers advantages while at the same time exposing them to pitfalls in clinical practice. We also explain how the virtues of courage, ${ }^{23}$ diligence, and curiosity could help practitioners avoid the hazards that attend excessive tolerance and intolerance for uncertainty. Ultimately, we conclude that medicine has room for both tolerant and intolerant practitioners and that medical 
educators should focus on helping trainees cultivate these virtues rather than solely focusing on increasing tolerance or reducing intolerance for uncertainty per se.

In making this case, we characterize tolerance for uncertainty as comfort in the face of one's subjective perception of one's own ignorance about some aspect of a clinical situation. We follow Ilgen et al. who write that comfort "references confidence in one's capabilities to act (or not act) in a safe and effective manner given the situation." 20

\section{EXTREMES OF TOLERANCE AND INTOLERANCE FOR UNCERTAINTY}

In this section, we present brief sketches of extremely uncertainty-tolerant and uncertainty-intolerant physicians. We are not making empirical claims about any actual practitioners. Tolerance and intolerance for uncertainty are not binary; a physician's comfort with incomplete information is best measured on a spectrum. Indeed, it fluctuates from patient to patient. The following is meant merely as a thought exercise - a philosophical exploration of extremes that can help us to clarify the real-life virtue and wisdom that lies between the two poles. In employing this argumentative structure, made famous by Aristotle in his work on the virtues, ${ }^{24}$ we are not suggesting that either sketch represents a mode of actual medical practice. Rather, we are aiming to give readers a clearer sense of the most dramatic expressions of two sorts of dispositions, as well as their benefits and dangers. Ultimately, searching for a mean between these two extremes will help illuminate possible pitfalls both tolerant and intolerant practitioners face and to sharpen our thinking about how we might teach our students and residents to sidestep them.

\section{THE UNCERTAINTY-TOLERANT CLINICIAN}

Imagine an extremely uncertainty-tolerant physician. How might such a practitioner respond in the face of uncertainty? This philosophical exercise admits more than one kind of answer, of course, but consider the following sketch:

First, extremely tolerant physicians would be likely to perceive the limitations of their knowledge. Because they are comfortable with incomplete information, they will not distort the facts of the case to make them fit patterns they better understand.

Second, extremely tolerant physicians would feel comfortable proceeding in the face of uncertainty without panicking or feeling burdened or bothered by gaps in their understandings.

As a result, third, they would be likely to be honest with their patients about what they did not know. They would feel no need to hide or compensate for their lack of knowledge, and this openness could help to promote communication and trust between them and their patients. This disposition may make it easy for them to meet their obligations of honesty when interacting with patients and families.
Fourth, extremely tolerant physicians, not fearing what is unknown or poorly understood, would not be afraid to confront new problems and challenges they did not fully grasp. While they would not shy away from the unknown out of fear, this does not mean that they would always engage with new problems.

At this point, it may seem that such physicians would be paragons of virtue. And indeed, we ought to encourage young doctors to be honest about the limits of their knowledge, ${ }^{22,25}$ develop strong interpersonal skills, be honest and forthcoming in their interactions with patients, ${ }^{23,26}$ and not shy away from new challenges. Unfortunately, the portrait of the extremely uncertainty-tolerant physician has some less attractive features as well.

Fifth, people who tolerate uncertainty might lapse into a contented stagnation that results in poor practice. Recall that comfort with uncertainty is characterized by confidence in one's ability to act (or not act) in the face of one's subjective recognition of incomplete information. In the extreme, such a disposition could result in careless, lazy, and ill-considered behavior: those who are too comfortable with incomplete information may be tempted to proceed when they should not.

Relatedly, sixth, extremely tolerant physicians may be less likely to ask for help from more experienced or knowledgeable colleagues. Such providers would not be ashamed to admit their lack of knowledge, but when one is totally at peace with one's ignorance, seeking assistance can seem like a waste of time and energy, and an unnecessary imposition on others. This might be especially true in a busy practice or hospital with harried colleagues.

Seventh, tolerant physicians might be unmotivated to dig deeply into medical scholarship to learn more about the symptoms and conditions that generated uncertainty. While less tolerant physicians' gnawing anxieties might drive them to consult colleagues and journals, their extremely tolerant counterparts may be content to take their best guesses and move on, especially if pressed for time.

\section{THE UNCERTAINTY-INTOLERANT CLINICIAN}

What about an extremely uncertainty-intolerant physician whose tolerance for, and comfort with, uncertainty is extremely low? What sorts of attitudes and dispositions might we expect from such a practitioner?

First, where the tolerant physicians' comfort with uncertainty allowed them to recognize and accept elements of a case that outstripped their understandings, intolerant physicians may be disposed to simplify or mischaracterize confounding data in order to avoid the discomfort that attends their perceptions of uncertainty. The failure here is a kind of distorted perception: because of their anxiety, they (perhaps unconsciously) protect themselves from uncertain situations by representing them as more straightforward or familiar than they really are, raising the problem of premature closure in the diagnostic process. ${ }^{27}$ 
Supposing intolerant physicians are able to perceive their situations accurately, they may, second, be hesitant to act. At the limit, such practitioners may feel paralyzed by their lack of knowledge, unable to proceed in foggy conditions.

Third, intolerant physicians may be less than fully forthcoming and honest with patients. Unlike tolerant physicians, who feel no need to hide or compensate for their lack of knowledge, intolerant physicians may be tempted to present patients with half-truths or keep communication to a minimum until their cases become clearer. ${ }^{28}$

Fourth, intolerant physicians may shy away from new challenges, or even new data, that would lead to uncertainty and therefore cause anxiety. In the most extreme cases, this disposition could manifest itself in outright avoidance of new information.

Despite these disturbing flaws, there are elements of extremely intolerant clinicians' professional outlook that we may admire, at least to some extent.

Fifth, intolerant physicians (again assuming they could correctly perceive that the situation exceeded the limits of their understanding) would not be complacent about their lack of knowledge. Unlike extremely tolerant physicians, intolerant clinicians would be especially thorough and deeply concerned to do their best to act safely.

Along the same lines, sixth, the intolerant physicians' unwillingness to act when unsure of themselves might make them more likely to ask for help from more experienced and knowledgeable colleagues.

Seventh, intolerant physicians, motivated to ease their anxiety and discomfort, may go "above and beyond" to educate themselves in response to, or in preparation for, uncertain clinical situations. Indeed, their perceptions of their own incomplete understandings could push them to become highly knowledgeable and diligent caregivers, or even drive them to make scientific discoveries.

\section{FIGHT OR FLIGHT}

It is difficult to see how anyone who considers these two caricatures could conclude that either represents an entirely attractive ethical ideal. While extreme, they draw attention to characteristic ways in which even milder tolerance and intolerance for uncertainty may lead to poor practice when they appear in real-life clinicians. Thinking of uncertainty on the model of a threat ${ }^{7,29,30}$ may shed light on these patterns.

Roughly speaking, one may respond to threats by fighting or fleeing. ${ }^{7,30}$ It seems the most serious pitfalls associated with intolerance for uncertainty tend to stem from the flight rather than the fight response. The tendency to distort uncertain situations in order to avoid having to confront them is a means of avoidance rather than confrontation. ${ }^{7,30}$ The same is true of apprehension or paralysis in the face of uncertainty, as well as unwillingness to honestly discuss uncertain situations with patients. $^{28}$
As we saw, however, a person who becomes anxious when confronted with uncertainty may choose to "fight" rather than flee. A clinician's intolerance for uncertainty may motivate her to comb the medical literature for the latest scholarship, to ask patients more probing questions and listen more carefully to their answers, or to ask more experienced colleagues for guidance. ${ }^{23,25,26}$ These are all ways that actual practitioners may confront the threat of uncertainty head on. One significant implication of this analysis is that intolerance for uncertainty is not a trait we should try to eliminate or dilute in young doctors. In fact, so long as intolerant practitioners learn to fight their tendency to flee from uncertainty, this disposition can be an asset.

Physicians who are tolerant of uncertainty will face a different set of difficulties. These practitioners will not see uncertainty as a threat at all, and so they will not be as motivated to flee from it or to fight it. As a result, the pitfalls associated with high tolerance stem mostly from the physician's failure to see uncertainty as something worth overcoming. Here, the physician's comfort might nurture a kind of clinical indolence or inattention to detail that would be psychologically unsustainable for her angst-ridden counterparts.

\section{THREE CORRECTIVE VIRTUES}

The philosopher Philippa Foot wrote that virtues are correctives to human tendencies that make it difficult for us to act well. ${ }^{31}$ While excellent clinical practice requires a wide range of virtues, we highlight three virtues we believe would help physicians avoid the specific uncertainty-related pitfalls we have been discussing: Courage corrects for the tendency to "flee" from uncertainty too hastily; diligence mitigates the impulse to give into it too easily; curiosity inspires practitioners of all tolerance levels to confront it productively.

\section{Courage}

We have argued that the pitfalls associated with a low tolerance for uncertainty stem largely from the intolerant physician's impulse to "flee" from rather than "fight" uncertainty. Practitioners' anxiety about uncertainty may even manifest itself, via an unconscious mechanism of self-protection, in a tendency to distort their perceptions of data to make them fit neatly into identifiable patterns. Courage is the virtue that guards against the tendency to flee from threats that one ought to combat. The intolerant but courageous physician will be able to recognize uncertain terrain and take it on. ${ }^{25,26}$ To be clear, the virtue of courage is not expressed in false bravado. Rather, it allows one to perceive uncertain clinical situations accurately and to cultivate an inner reserve of strength to face new challenges.

There is a limit, however, of the usefulness of the fight-orflight model of uncertainty intolerance. Even when they are committed to identifying and courageously facing uncertain situations, it is inevitable that clinicians will often be 
confronted by uncertainty even when the "fight" is over. In these cases, some level of uncertainty must simply be tolerated. Thus, we should underscore that while there is room in medicine for both tolerant and intolerant practitioners, living the clinical life of the extremely intolerant physician would be untenable. Although intolerance for uncertainty can be an asset, medical educators must nevertheless teach their uncertainty-intolerant trainees when to stop fighting and to accept their own limitations and develop strategies to manage clinical uncertainty. ${ }^{4,22,25,26,32}$

\section{Diligence}

How might we combat the tendency in extremely tolerant physicians to take uncertainty too lightly? The relevant failure in the extreme cases we sketched above was a lack of motivation that sprung from one's comfort with incomplete knowledge. The corrective here is diligence, a trait that would inspire even the most uncertainty-tolerant physicians to take reasonable steps to increase their knowledge when pressed up against the limits of their expertise. A diligent physician would not be content to throw up her hands and proceed with her best guess when she owed her patients more. She would feel compelled to seek guidance from more knowledgeable colleagues when appropriate, ${ }^{33}$ and she would stay on top of relevant scholarship and guidelines for best practice. Diligence may also help uncertaintyintolerant physicians perceive uncertainty, if they have a distorted perception resulting from a self-protective "flight" response, and guard against premature closure.

\section{Curiosity}

The virtue of curiosity has the potential to correct for the shortcomings of both the extremely tolerant and intolerant physicians. The operations of this trait will orient practitioners on both ends of the spectrum toward engagement with medical and scientific scholarship. Rather than fleeing from uncertainty, intolerant but curious physicians will channel their uneasiness with incomplete knowledge toward enriching study and advancement. Curious physicians with higher tolerances for uncertainty will be motivated to increase their knowledge even though they do not experience the nagging insecurities that might push their uncertaintyintolerant counterparts to do the same.

\section{IMPLICATIONS FOR MEDICAL EDUCATION}

So far, we have argued that, while neither extreme tolerance nor extreme intolerance of uncertainty is ideal, neither temperament needs be entirely rejected or discouraged. Rather, both dispositions require the regulation of certain virtues that all trainees would do well to cultivate. Having shown that there is a place in medicine for both uncertainty-tolerant and uncertainty-intolerant physicians, we will conclude with some brief remarks about how we as medical educators might aspire to better guide and teach our learners.

It is inevitable that, as physicians proceed through their careers, they will experience varying degrees and types of uncertainty. We and others argue that the current system of rewards in medical education must shift from one that overlooks or denies the existence of uncertainty ${ }^{21,28,34}$ to one that embraces it. ${ }^{3,4,22,35}$ We identify a few opportunities—outside the formal curriculum - to promote this necessary cultural change.

\section{REFLECT ON UNCERTAINTY DURING THE ADMISSIONS PROCESS}

Anticipation of and resilience to experiences of uncertainty in medicine require physicians to understand their own responses to uncertainty. ${ }^{1,22}$ The opportunity to engage in self-reflection and cultivate self-awareness can begin as early as the medical admissions process. In light of evidence that tolerance for uncertainty is highly variable among matriculants to medical school, ${ }^{1,36,37}$ there have been calls to consider tolerance for uncertainty in the medical admissions process. ${ }^{38}$ Admissions committees may disagree about the necessity or practicality of exploring applicants' reactions to uncertainty; however, they ought to consider whether and how incorporating an exploration of applicants' reactions to uncertainty fits their goals and situation. Where such exploration does take place, applicants' responses should not be evaluated as a condition of admission but as an exercise in self-awareness. The goal would be for admissions committees to encourage applicants to reflect on and disclose experiences of uncertainty, not to judge these experiences.

\section{SUPPORT AWARENESS OF UNCERTAINTY AND DEVELOPMENT OF VIRTUES}

Medical educators should also facilitate the development of the three virtues we note. Virtue cultivation is a difficult task that must begin early. ${ }^{31,39}$ While education cannot reshape students' personalities, there are concrete steps we might take to facilitate the development of traits that we have emphasized. $^{22,39,40}$

Courage. It is crucial to specify that courage should not mean confronting the challenges of uncertainty all by oneself. One way to "fight" uncertainty is to call for reinforcements. ${ }^{22,25}$ Indeed, encouraging clinicians to ask for help in analyzing and treating patients would foster courage and promote a clear perception of uncertainty and a willingness to confront it. If a young uncertainty-intolerant doctor knew, for example, that she would be commended rather than disparaged for admitting that a situation extended beyond her knowledge, she might not feel the (perhaps unconscious) need to protect herself from uncertain situations. Thus, to promote the virtue of courage, we may need 
to help attending physicians, and other educators, to be more generous, patient, and encouraging. ${ }^{22}$

Diligence. Like many other virtues, diligence may be thought of as a mean between two extremes. Here, we have emphasized its ability to guard against what we called "contented stagnation," but there are excesses in the opposite direction. Compulsive perfectionism is its own kind of departure from ideal caregiving. We should encourage trainees to be diligent by rewarding them for being careful rather than for demonstrating the perfectionism that interferes with well-being. To this end, we should engage in frank discussions with trainees about working beyond expected duty hours and guide them in the balance between the two extremes.

Curiosity. As educators, we should encourage a love of learning and exploration for its own sake, as this attitude is central to the virtue of curiosity. Indeed, it has been argued that promoting curiosity is one of the ways to guide trainees toward greater tolerance for uncertainty. ${ }^{22}$ It is regrettable when trainees, feeling ground down by the demands of medical education, lose this virtue or feel they have no time to exercise it. ${ }^{41}$ It is our job to nurture their curiosity by designing curricula that give them time and inspiration to experience the thrill of medical discovery ${ }^{22,40}$ and to develop programs to sustain this curiosity in practice. ${ }^{32,42}$ Moreover, Valbuena et al. argue that a positive inquiry attitude is essential for physicians and a determinant of their engagement in adaptive behaviors ${ }^{43}$

\section{CONSIDER TOLERANCE FOR UNCERTAINTY IN CAREER MENTORSHIP}

Tolerance for uncertainty is associated with specialty choice. ${ }^{1,29,36}$ Undoubtedly, there is self-selection, but specialty choices may or may not reflect students' self-awareness of their tolerance for uncertainty and how it fits with the demands of their chosen field. Medical educators should consider students' tolerance for uncertainty in advising them about specialty choice. Two features of specialties might be relevant here.

Stakes. Fields that involve procedures that are risky or have high stakes may attract clinicians who are less tolerant of uncertainty. Patients undergoing surgical procedures, for example, might benefit from an almost perfectionist attention to detail, assuming this intolerance for uncertainty does not manifest itself in a distorted perception. By the time a patient undergoes surgery, the surgical team tends to have a clear, if provisional, diagnosis. Generalist fields (e.g., internal and family medicine), on the other hand, are rife with uncertainty that may not immediately call for such clarity. ${ }^{6,20}$
Time Pressure. Certain medical specialties may be more challenging than others for uncertainty-intolerant clinicians. In emergency surgery, for example, when there is little time to deliberate, comb library archives, or ask for help from experts, uncertainty will simply have to be tolerated. Medical subspecialties such as nephrology and oncology that require careful scrutiny of a small number of complex cases over time may reward the dogged assiduousness of the curious but uncertainty-intolerant practitioner. On the other hand, the family physician seeing 16 to 20 patients in a day may have to tolerate the uncertainty posed by some patients.

This is not to say that uncertainty-intolerant physicians should not pursue family medicine or that uncertaintytolerant physicians should not pursue surgery. Rather, we suggest that, first, there are places in medicine for clinicians with a wide range of reactions to uncertainty, and, second, certain matches between specialty and clinician may require a persistent and powerful effort at virtue cultivation in order to succeed. Ultimately, the onus is on us to help our trainees achieve this success.

\section{CONCLUSIONS}

Using a normative approach, we find that tolerance and intolerance of uncertainty have pitfalls, as well as advantages. Acknowledging uncertainty and cultivating virtues such as courage, diligence, and curiosity could help clinicians avoid the dangers of excessive tolerance and intolerance of uncertainty. New or revamped educational programs and teaching strategies, spanning from matriculation through completion of training, should encourage trainees to acknowledge uncertainty and their reactions to it and help them develop virtues to manage the uncertainty inherent in medicine.

Corresponding Author: Martha S. Gerrity, MD, MPH, PhD; Division of General Medicine and Geriatrics, Oregon Health and Sciences University, OR Portland, USA (e-mail: martha.gerrity@va.gov).

\section{Compliance with Ethical Standards:}

Conflict of Interest: The authors declare that they do not have a conflict of interest.

Ethical Approval: Not applicable.

\section{REFERENCES}

1. Geller G, Faden RR, Levine DM. Tolerance for ambiguity among medical students: implications for their selection, training and practice. Soc Sci Med 1990;31(5):619-624.

2. Gerrity MS, White KP, DeVellis RF, Dittus RS. Physicians' Reactions to Uncertainty: Refining the Constructs and Scales. Motiv Emot 1995;19(3):175-191. https://doi.org/10.1007/BF02250510

3. Armstrong $\mathbf{K}$. If You Can't Beat It, Join It: Uncertainty and Trust in Medicine. Ann Intern Med 2018;168(11):818-819. https://doi.org/10. 7326/M18-0445

4. Simpkin AL, Schwartzstein RM. Tolerating uncertainty-the next medical revolution? N Engl J Med 2016;375(18):1713-1715. 
5. Fox RC. The Evolution of Medical Uncertainty. Milbank Mem Fund $Q$ Health Soc 1980;58(1):1-49. https://doi.org/10.2307/3349705

6. Gerrity MS, DeVellis RF, Light DW. Uncertainty and Professional Work: Perceptions of Physicians in Clinical Practice. Am $J$ Sociol 1992;97(4): 1022-1051. https://doi.org/10.1086/229860

7. Furnham A, Marks J. Tolerance of ambiguity: a review of the recent literature. Psychology. 2013;4(09):717-728.

8. Hall KH. Reviewing intuitive decision-making and uncertainty: the implications for medical education. Med Educ 2002;36(3):216-224.

9. Smithson M. Ignorance and Uncertainty: Emerging Paradigms. Springer Science \& Business Media; 2012.

10. Helou MA, DiazGranados D, Ryan MS, Cyrus JW. Uncertainty in decision making in medicine: a scoping review and thematic analysis of conceptual models. Acad Med 2020;95(1):157-165.

11. Moulton CE, Regehr G, Mylopoulos M, MacRae HM. Slowing down when you should: a new model of expert judgment. Acad Med 2007;82(10 Suppl):S109-S116.

12. Djulbegovic B, Hozo I, Greenland S. Uncertainty in clinical medicine. In: Gifford F, ed. Handbook of Philosophy of Science: Philosophy of Medicine. Elsevier; 2011:299-356.

13. Tonelli MR, Upshur REG. A philosophical approach to addressing uncertainty in medical education. Acad Med 2019;94(4):507-511.

14. Hillen MA, Gutheil CM, Strout TD, Smets EM, Han PK. Tolerance of uncertainty: conceptual analysis, integrative model, and implications for healthcare. Soc Sci Med 2017;180:62-75.

15. Strout TD, Hillen M, Gutheil C, et al. Tolerance of uncertainty: a systematic review of health and healthcare-related outcomes. Patient Educ Couns 2018;101(9):1518-1537.

16. Hunter DJ. Uncertainty in the era of precision medicine. $N$ Engl $J$ Med 2016;375(8):711-713

17. Simpkin AL, Khan A, West DC, et al. Stress From uncertainty and resilience among depressed and burned out residents: a cross-sectional study. Acad Pediatr 2018;18(6):698-704.

18. Bovier PA, Perneger TV. Stress from uncertainty from graduation to retirement-a population-based study of Swiss physicians. J Gen Intern Med 2007;22(5):632-638

19. Simpkin AL. Embracing uncertainty: could there be a blueprint from COVID-19? thebmjopinion. Published April 16, 2020. Accessed December 1, 2020. https://doi.org/https://blogs.bmj.com/bmj/2020/04/16/ embracing-uncertainty-could-there-be-a-blueprint-from-covid-19/

20. Ilgen JS, Eva KW, de Bruin A, Cook DA, Regehr G. Comfort with Uncertainty: Reframing Our Conceptions of How Clinicians Navigate Complex Clinical Situations. Adv Health Sci Educ Theory Pract 24(4):797-809. https://doi.org/10.1007/s10459-018-9859-5

21. Atkinson P. Training for certainty. Soc Sci Med 1984;19(9):949-956.

22. Gheihman G, Johnson M, Simpkin AL. Twelve tips for thriving in the face of clinical uncertainty. Med Teach. 2020;42(5):493-499.

23. Davis DLF, Chou CL. The bearable lightness of uncertainty. J Gen Intern Med 2019;34(11):2293-2294.

24. Aristotle., Ross WD, Brown L. The Nicomachean Ethics. Published 2009. Accessed January 19, 2021. https://www.worldcat.org/title/ nicomachean-ethics/oclc/495988989

25. Ilgen JS, Teunissen PW, de Bruin A, Bowen JL, Regehr G. Warning bells: how clinicians leverage their discomfort to manage moments of uncertainty. Med Educ. Published online 2020. https://doi.org/10.1111/ medu. 14304
26. Berger Z. Navigating the unknown: shared decision-making in the face of uncertainty. J Gen Intern Med 2015;30(5):675-678.

27. Saposnik G, Redelmeier D, Ruff CC, Tobler PN. Cognitive biases associated with medical decisions: a systematic review. BMC Med Inform Decis Mak 2016;16(1): 138

28. Katz J. Why doctors don't disclose uncertainty. Hastings Cent Rep 1984:35-44. PMID: 6715153.

29. Gerrity MS, DeVellis RF, Earp JA. physicians' reactions to uncertainty in patient care: a new measure and new insights. Med Care 1990;28(8):724-736.

30. Stanley Budner. Intolerance of ambiguity as a personality variable. $J$ Pers 1962;30(1):29-50

31. Foot P. Virtues and Vices and Other Essays in Moral Philosophy. Oxford University Press, 2003. Oxford Scholarship Online, 2003. Accessed December 1, 2020. https://doi.org/10.1093/0199252866.001.0001.

32. Sommers LS, Morgan L, Johnson L, Yatabe K. Practice inquiry: clinical uncertainty as a focus for small-group learning and practice improvement. J Gen Intern Med 2007;22(2):246-252.

33. Ilgen JS, Bowen J, de Bruin A, Regehr G, Teunissen P. "I was worried about the patient, but I wasn't feeling worried”: how physicians judge their comfort in settings of uncertainty. Acad Med 2020;95(11S):S67-S72.

34. Luther VP, Crandall SJ. Commentary: ambiguity and uncertainty: neglected elements of medical education curricula? Acad Med 2011:86(7):799-800.

35. Ofri D. Medical humanities: the Rx for uncertainty? Acad Med 2017;92(12):1657-1658

36. DeForge BR, Sobal J. Intolerance of ambiguity in students entering medical school. Soc Sci Med 1989;28(8):869-874

37. Geller G, Grbic D, Andolsek KM, Caulfield M, Roskovensky L Tolerance for ambiguity among medical students: patterns of change during medical school and their implications for professional development. Acad Med. 2020. https://doi.org/10.1097/ACM. 0000000000003820 .

38. Geller G. Tolerance for ambiguity: an ethics-based criterion for medical student selection. Acad Med 2013;88(5):581-584.

39. Seoane L, Tompkins LM, De Conciliis A, Boysen PG. Virtues education in medical school: the foundation for professional formation. Ochsner $J$ 2016;16(1):50-55.

40. Geller G, Caldwell M, Merritt M. The cultivation of wonder in the premedical learning environment: nurturing ethical character in the early formation of health professionals. J Coll Charact 2018; 19(3):229-235.

41. Sternszus R, Saroyan A, Steinert Y. Describing medical student curiosity across a four year curriculum: an exploratory study. Med Teach 2017;39(4):377-382.

42. Sommers LS, Launer J, eds. Clinical Uncertainty in Primary Care: The Challenge of Collaborative Engagement. Springer; 2013.

43. Valbuena G, O'Brien B, ten Cate O, O'Sullivan P. Inquiry in the medical curriculum: a pedagogical conundrum and a proposed solution. Acad Med 2019;94(6):804-808.

Publisher's Note: Springer Nature remains neutral with regard to jurisdictional claims in published maps and institutional affiliations. 